Portland State University

PDXScholar

\title{
Divergent trends in ecosystem services under different climate-management futures in a fire-prone forest landscape
}

\author{
Joshua S. Halofsky \\ Washington State Department of Natural Resources \\ Jessica E. Halofsky \\ University of Washington \\ Miles A. Hemstrom \\ Portland State University \\ Anita T. Morzillo \\ University of Connecticut \\ Xiaoping Zhou \\ U.S. Department of Agriculture Forest Service
}

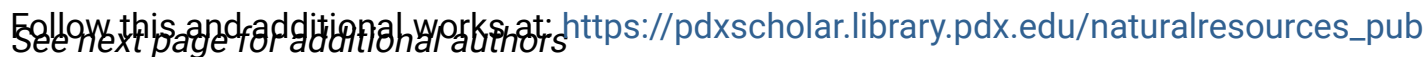

Part of the Environmental Sciences Commons, and the Forest Sciences Commons Let us know how access to this document benefits you.

\section{Citation Details}

Halofsky, J. S., Halofsky, J. E., Hemstrom, M. A., Morzillo, A. T., Zhou, X., \& Donato, D. C. (2017). Divergent trends in ecosystem services under different climate-management futures in a fire-prone forest landscape. Climatic Change, 142(1-2), 83-95.

This Article is brought to you for free and open access. It has been accepted for inclusion in Institute for Natural Resources Publications by an authorized administrator of PDXScholar. Please contact us if we can make this document more accessible: pdxscholar@pdx.edu. 
Authors

Joshua S. Halofsky, Jessica E. Halofsky, Miles A. Hemstrom, Anita T. Morzillo, Xiaoping Zhou, and Daniel C. Donato 


\title{
Divergent trends in ecosystem services under different climate-management futures in a fire-prone forest landscape
}

\author{
Joshua S. Halofsky ${ }^{1}$ - Jessica E. Halofsky ${ }^{2}$. \\ Miles A. Hemstrom ${ }^{3,4}$ - Anita T. Morzillo ${ }^{5}$. \\ Xiaoping Zhou ${ }^{4}$ - Daniel C. Donato ${ }^{1,2}$
}

Received: 18 March 2016 / Accepted: 10 February 2017 / Published online: 28 February 2017

(C) Springer Science+Business Media Dordrecht 2017

\begin{abstract}
While ecosystem services and climate change are often examined independently, quantitative assessments integrating these fields are needed to inform future land management decisions. Using climate-informed state-and-transition simulations, we examined projected trends and tradeoffs for a suite of ecosystem services under four climate change scenarios and two management scenarios (active management emphasizing fuel treatments and no management other than fire suppression) in a fire-prone landscape of dry and moist mixed-conifer forests in central Oregon, USA. Focal ecosystem services included fire potential (regulating service), timber volume (provisioning service), and potential wildlife habitat (supporting service). Projections without climate change suggested active management in dry mixed-conifer forests would create more open forest structures, reduce crown fire potential, and maintain timber stocks, while in moist mixed-conifer forests, active management would
\end{abstract}

Electronic supplementary material The online version of this article (doi:10.1007/s10584-017-1925-0) contains supplementary material, which is available to authorized users.

Joshua S. Halofsky

joshua.halofsky@dnr.wa.gov

1 Washington State Department of Natural Resources, 1111 Washington Street SE, PO Box 47014, Olympia, WA 98504-7016, USA

2 School of Environmental and Forest Sciences, University of Washington, PO Box 352100, Seattle, WA 98195-2100, USA

3 Institute for Natural Resources, Portland State University, PO Box 751, Portland, OR 97207-0751, USA

4 U.S. Department of Agriculture Forest Service, Pacific Northwest Research Station, 620 SW Main, Suite 400, Portland, OR 97205, USA

5 Department of Natural Resources and the Environment, University of Connecticut, 1376 Storrs Rd., Storrs, CT 06269, USA 
reduce crown fire potential but at the expense of timber stocks. When climate change was considered, however, trends in most ecosystem services changed substantially, with large increases in wildfire area predominating broad-scale trends in outputs, regardless of management approach (e.g., strong declines in timber stocks and habitat for closed-forest wildlife species). Active management still had an influence under a changing climate, but as a moderator of the strong climate-driven trends rather than being a principal driver of ecosystem service outputs. These results suggest projections of future ecosystem services that do not consider climate change may result in unrealistic expectations of benefits.

\section{Introduction}

Climate change, and its effects on disturbance regimes, is likely to influence a variety of different ecosystem services, including regulating, provisioning, and supporting ecosystem services (Fischlin et al. 2007; Groffman et al. 2014; Seidl et al. 2016). Effects of climate change on ecosystem services is sometimes difficult to predict because of the variety factors upon which each ecosystem service depends (Groffman et al. 2014), because tradeoffs among different ecosystem services may change through time, and because ecosystem service tradeoffs vary depending in part on landscape geography, management strategies, future climate, and ecosystem service studied (Tempereli et al. 2012; Elkin et al. 2013; Mina et al. 2016). Yet integrated and quantitative analyses are needed to assess potential effects of climate change on multiple ecosystem services if society is to attempt to provide sustainable levels of ecosystem services into the future.

Increasing disturbance frequency and severity will be especially important to consider in ecosystem management under changing climate. Promoting the resilience of ecosystems to increased disturbance can help to sustain some level of ecosystem services, especially in systems with historically more frequent disturbance return intervals (Adams 2013; Stephens et al. 2014; Millar and Stephenson 2015; Seidl et al. 2016). For example, in the Pacific Northwestern USA, many fire-prone forests have been compositionally and structurally altered after decades of fire suppression and forest management, resulting in greater risk of standreplacing wildfire (Merschel et al. 2014; Stine et al. 2014; Hessburg et al. 2016). Climate change is likely to further increase this risk by increasing area burned (Littell et al. 2010; Stavros et al. 2014). Recent management recommendations have therefore focused on creating more heterogeneous landscapes with greater area of open forest, through actions such as thinning and prescribed fire (Hessburg et al. 2016). Such active management of frequent fire forests can prevent high-severity fire that, in concert with other stressors such as drought, might force a system to cross a threshold and change states (dominant vegetation) (Millar and Stephenson 2015). While these actions may promote forest resilience, active management is also likely to have negative consequences for some ecosystem services, such as wildlife habitat for species dependent on dense forest structure. Examining these potential tradeoffs under more frequent disturbance regimes will be important to both inform management and to help manage societal expectations for ecosystem services, such as timber supply, under changing climate.

Here, we describe a unique integrated assessment that evaluates potential effects of climate change and land management (and their interactions) on ecosystem services, including reduction in crown fire potential (regulating service), timber volume (provisioning service), and potential wildlife habitat (supporting service), in a central Oregon landscape. This suite of ecosystem services is a subset of values associated with management objectives on public 
forestlands in the western USA and other regions (Federal Register 2012) and was purposely selected to more broadly illustrate trends across different types of ecosystem service categories. We used a linked-model approach that incorporates future climate projections, natural disturbances, vegetation dynamics, and management actions (Halofsky et al. 2013, 2014b) and connects to parallel analyses for ecosystem services. Through this integrated approach, we asked the question: How do trends and the narrative associated with several ecosystem services vary under different climate and management assumptions?

\section{Methods}

\subsection{Study area}

The central Oregon study area is composed primarily of dry and moist mixed-conifer forests, which are differentiated by fire regime and species composition. The dry mixed-conifer forests are dominated by ponderosa pine (Pinus ponderosa) and lodgepole pine (Pinus contora Dougl.), with the latter often associated with deep pumice soils. Such forests historically had a fire return interval of 10-25 years (Stine et al. 2014), and fires were typically low severity. At higher elevations in the study area, moist mixed-conifer forests are composed of ponderosa pine as an early-seral species, and both Douglas-fir (Psuedotsuga menzziesii) and white fir (Abies concolor) as late seral species. With a mean natural fire return interval of $\sim 20-50$ years, moist mixed-conifer forests were historically characterized by mixed-severity fire regimes, although patches of low- and high-severity wildfire were not uncommon (Stine et al. 2014). Within our study extent, these mixed-conifer forests range in elevation between 800 and $1800 \mathrm{~m}$. Annual dry and moist mixed-conifer forest precipitation ranges from 32-155 to 47$227 \mathrm{~cm}$ (PRISM Group 2012), respectively, with most precipitation falling as rain or snow during the winter months. Maximum summer temperatures at the lowest elevations may exceed $30{ }^{\circ} \mathrm{C}$ (PRISM Group 2012).

\subsection{Climate data}

We used the Parameter-elevation Regressions on Independent Slopes Model (PRISM) climate data set on a 30-arc second grid ( 800 -m grain; Daly et al. 2008) to represent historical climate. For future climates, we selected three global climate models run under the A2 emissions scenario (Nakićenović and Swart 2000) from the Intergovernmental Panel on Climate Change Fourth Assessment Report (IPCC 2007). The three global climate models (GCMs), CSIRO Mk3 model (Gordon et al. 2002), MIROC 3.2 medres model (Hasumi and Emori 2004), and Hadley CM3 model (Gordon et al. 2002; Johns et al. 2003), were selected to span a range of potential temperature and precipitation changes. Of the three GCMs, CSIRO projects the greatest precipitation increase and smallest temperatures increase, whereas MIROC and Hadley can be respectively described as the hot and wet and hot and dry climate scenarios. Temperature increases are greatest during the summer for all the three GCMs, although temperatures increase year round; precipitation increases in the winter and decreases during the summer (Rogers et al. 2011). We used existing downscaled GCM data from Halofsky et al. (2013), who applied the "delta" method (Fowler et al. 2007) to downscale gridded GCM anomaly data to $\sim 800-\mathrm{m}$ resolution. This downscaled data were then used as input into the MC1 dynamic global vegetation model. 


\subsection{The MC1 model}

The MC1 model is a dynamic global vegetation model that integrates climate data with fundamental ecological processes such as competition for nutrients, water and light, and carbon and water uptake and losses (Bachelet et al. 2001). MC1 runs three sub-models: a biogeochemistry model, a biogeography model, and a wildfire model (Bachelet et al. 2001). The initial MC1 calibration for the study area included the use of historic PRISM data, and spatially relating $\mathrm{MC1}$ plant physiognomic classes to existing maps of current potential vegetation types. The final calibration resulted in a $92-100 \%$ agreement between MC1 projections of plant physiognomic classes and pre-existing maps of potential vegetation types originally developed from statistical relationships between field plots and the biophysical setting (Henderson et al. 2011; Halofsky et al. 2013). Once calibrated, MC1 projected wildfire and vegetation trends with input from the three GCMs for the years 2010 to 2100.

One limitation of $\mathrm{MC1}$ is that it does not currently integrate management, although recent work has begun to incorporate simplified rules of land use (Bachelet et al. 2015). In addition, $\mathrm{MC1}$ represents vegetation as potential vegetation classes (e.g., temperate needle-leaved forest) with a biogeography ruleset driven in part by annual average minimum monthly temperature and growing season precipitation (Bachelet et al. 2001). These broad potential vegetation classes can therefore rapidly change depending on temperature and precipitation projections. Any inherent plant resistance or resilience to climate change (e.g., inertia of a vegetation type until disturbance occurs) is consequently not modeled within $\mathrm{MC1}$. Both MC1 limitations were overcome by linking $\mathrm{MC} 1$ trends with state-and-transition simulation models.

\subsection{State-and-transition simulation models}

We utilized state-and-transition simulation models (STSMs; Daniel and Frid 2012) originally developed by local specialists, and subsequently modified and consolidated for the Integrated Landscape Assessment Project (Halofsky et al. 2014a). Each STSM was developed to represent a potential vegetation type, a unique combination of vegetation-dominant cover types and conditions, growth rates, and natural disturbance regimes that characterize a distinct climate space. All vegetative conditions, represented as discrete structural states in the forested STSMs, were defined using a consistent ruleset based on tree diameter, percent canopy cover, and canopy layers (Halofsky et al. 2013). We used this ruleset to classify an existing 30-m vegetation cover type and structure map (https://lemma.forestry.oregonstate.edu; Ohmann and Gregory 2002) to develop our modeled initial conditions. Post-disturbance conditions were also included in each STSM, representing live trees of a certain diameter range in addition to standing snags and downed wood. All the models included natural disturbances, such as wildfire and insect-related mortality, with disturbance levels varying by STSM. All forested STSMs also included a suite of management transitions which varied by forest type and typically included pre-commercial thins, thins from below, regeneration harvests, salvage harvests, planting, and prescribed fire (see Table S1 for treatment details).

\subsection{Developing climate-informed STSMs}

We used spatial overlays of potential vegetation type maps, which had guided the development of STSMs, and MC1 potential vegetation classes, to determine which subset of potential vegetation types found in the study area best corresponded to each $\mathrm{MC1}$ vegetation class 
(Halofsky et al. 2013). In addition to identifying the subset of potential vegetation types through spatial overlays, MC1 vegetation projections were also used to determine which subset of STSMs should be linked with climate transitions. The resulting climate-informed STSMs (cSTSMs) developed for each climate scenario allowed the ebb and flow of vegetation across STSMs to vary with climate projections.

To develop climate transitions between individual STSMs, we first tallied the proportion of area annually departing each $\mathrm{MC1}$ potential vegetation class to every other vegetation class. For each climate scenario and $\mathrm{MCl}$ potential vegetation class, these departure calculations were computed annually for our simulation period (2010-2100) and then averaged across the entire simulation period. This average departure proportion, calculated between each pair of $\mathrm{MC1}$ vegetation classes, became the average transition probability connecting the corresponding pair of STSMs under a given climate scenario. Average transition probabilities connected post-disturbance and early-successional STSM states to functionally equivalent STSM states in each model pair assuming climate change transitions are most likely to occur from more open conditions following a stand-replacing disturbance. Yet this average transition value ignored that the climate effect changing vegetation types could be greater, or less, than the average in any given year.

We therefore developed a scaling factor to annually increase or decrease the mean transition probabilities in the cSTSMs. The scaling factor divided the annual departure proportion for each $\mathrm{MC1}$ potential vegetation class pair by the annual average transition probability for the same vegetation pair across the entire simulation period. The outcome of the calculation is a scaling factor (or trend multiplier) that proportionally increased or decreased the probability of a climate change transition occurring in any given year based on annual climate variability. We also developed cSTSM wildfire trend multipliers using an identical approach to vegetation scaling factors, but with MC1 output of annual fraction of grid cells burned. These wildfire trend multipliers were used to annually increase or decrease individual STSM wildfire probabilities for each climate scenario. Taken together, the average climate change vegetation transition probability and both climate change vegetation and wildfire trend multipliers ensure $\mathrm{MC} 1$ vegetation, and wildfire trends are captured by each cSTSM. But adopting the MC1 projections as probabilities within a cSTSM results in the likelihood of a climate change transition occurring as a "roll of the dice," dampening area burned and vegetation shifts relative to MC1 (Halofsky et al. 2013).

\subsection{Management scenarios}

We modeled two management scenarios: fire suppression and active management. The fire suppression scenario assumed no future management other than the continued suppression of wildfires. Under both management scenarios, future fire suppression was assumed to equal suppression success for the years 1984-2008 (Halofsky et al. 2013). The active management scenario included treatments to increase landscape resilience to wildfire in the dry and moist mixed-conifer vegetation types, such as prescribed fire and thinning from below. Treatment levels varied by forest type and were developed in collaboration with local ecologists (Online Resource Table S1). Treatments were intended to reduce tree density and fuel connectivity, and thereby to reduce the likelihood of stand-replacing wildfire. Although of negligible value as a resilience strategy, salvage harvest was also permitted to occur, reflecting the need for some economic return to help offset replanting costs. 


\subsection{Model runs}

While our initial conditions were developed from spatial data, we ran our models aspatially, using cSTSMs to track the amount of area within a state at a given time step, but without the ability to track individual pixels in space. We ran our four climate scenarios (projections from the three GCMs plus no climate change) with each of our two management scenarios, for a total of eight climate-management simulations. Each model run consisted of 90 annual time steps and 30 Monte Carlo simulations. Rather than examining each climate-management scenario separately, we combined the output from three of the four climate scenarios (CSIRO, Hadley, and MIROC) to examine a range of possible future conditions. This ensemble of potential futures was subsequently compared to our model runs without climate change. All the models were run with the Path simulation software ver. 3.04 (Apex RMS and ESSA Technologies 2011).

\subsection{Indicators of ecosystem condition and services}

We selected crown fire potential (CFP) reduction to represent changes in regulating ecosystem services (benefits from regulation of ecosystem processes) and standing timber volume as a provisioning ecosystem services (products obtained from ecosystems) (sensu Millennium Ecosystem Assessment 2005). In addition, we examined potential habitat for three wildlife species, the western bluebird (Sialia mexicana; "bluebird" hereafter), Pacific marten (Martes caurina, "marten" hereafter), and white-headed woodpecker (Picoides albolarvatus, "woodpecker" hereafter) to represent a supporting service (those necessary for production of other ecosystem services), with each species requiring distinct structural conditions. Methods describing the derivation of each service are summarized in supplemental online resources, and detailed descriptions of each indicator methodology can be found in Halofsky et al. (2014a).

\section{Results}

\subsection{Wildfire}

Without climate change, average cumulative area burned did not vary across management scenarios for either forest type, and the forest area remained constant throughout time (Fig. 1ad). However, active management shifted fire severity from primarily stand-replacing (more than $75 \%$ overstory tree mortality) to mostly mixed-severity (25-75\% overstory tree mortality).

In contrast, under a changing climate, the cumulative area burned was greater than the forest area for both vegetation types and management scenarios (Fig. 1e, f, g, h). There was greater loss of moist mixed-conifer forest under the fire suppression scenario (Fig. 1g) because there were more stand-replacing fires, which generated more climate-related opportunities for this forest to transition to a different vegetation type relative to active management (Fig. 1h).

\subsection{Forest structure}

Without climate change, fire suppression in dry mixed-conifer forests created a landscape dominated by dense forests, although post-disturbance and early-seral conditions existed across $\sim 30 \%$ of the forested area by the end of the simulation (Fig. 2a). In the absence of 


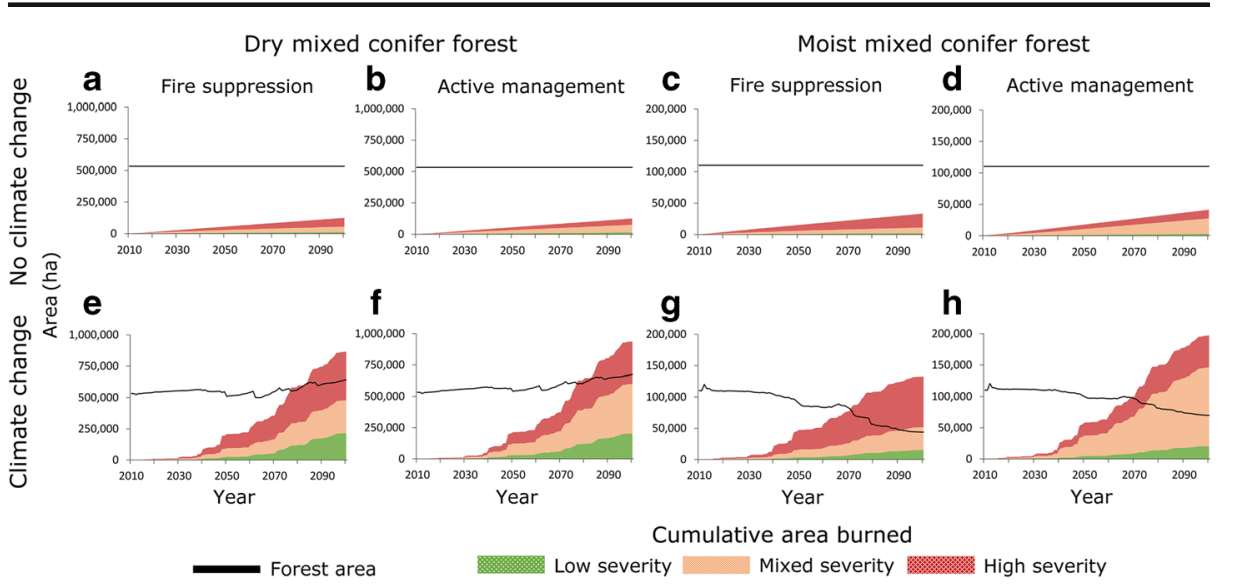

Fig. 1 Average trends in wildfire severity and forest type area under different climate-management scenarios. Wildfire trends illustrate cumulative area burned by severity class;forest area represents absolute values. Low severity represents less than $25 \%$ overstory morality, moderate severity represents $25-75 \%$ overstory mortality, and stand-replacing wildfire results in $>75 \%$ overstory mortality

climate change, active management in dry mixed-conifer forests reduced the amount of dense forest on the landscape (Fig. 2b). However, with increased fire under a changing climate, the dry mixed-conifer landscape became increasingly dominated by early-seral conditions (Fig. 2e, f), while active management maintained more area in large diameter, open forest relative to the no management scenario (Fig. 2f).

In moist mixed-conifer forest, dense forests composed at least half of the area regardless of future climate (Fig. 2c, d, g, h). However, under changing climate and the fire suppression scenario, an additional $20 \%$ of this forest type moved to post-disturbance and early-seral conditions by the end of the simulation (Fig. $2 \mathrm{~g}$ ). The increase in post-disturbance and earlyseral conditions was muted under the active management scenario (Fig. 2h), under which large proportions of the area became open forests with larger trees.

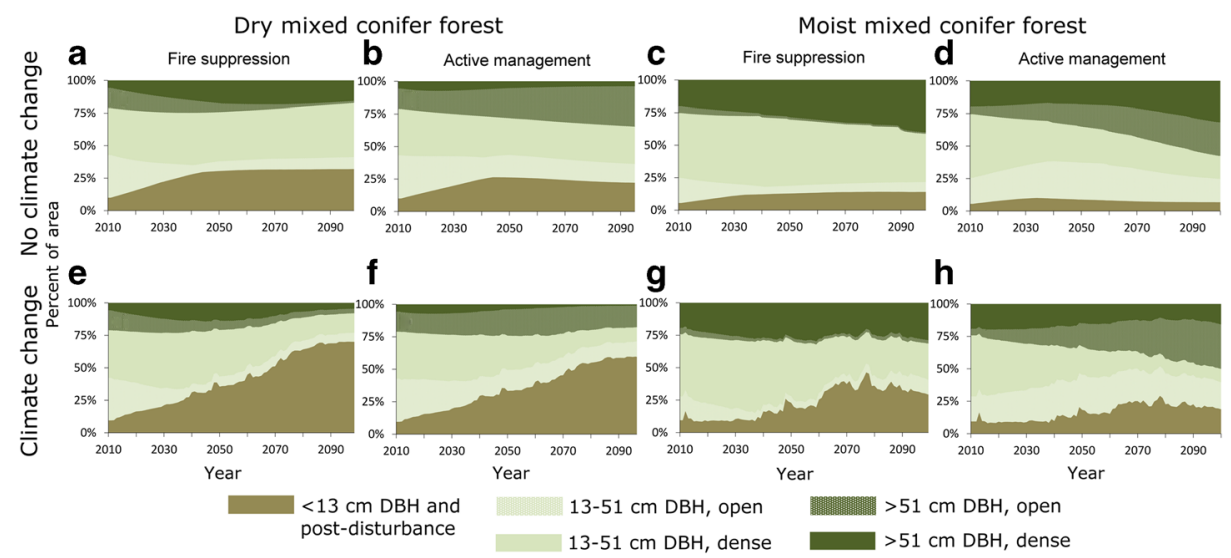

Fig. 2 Average percent trends in forest structure area under different climate-management scenarios. Dense forests include forests with more than $40 \%$ canopy cover. Open forests represent all single-story forests with less than $40 \%$ canopy cover. Post-disturbance forests include all forests and grasslands with standing snags and downed wood 


\subsection{Crown fire potential}

In dry mixed-conifer forests, without climate change, there was relatively little change in high CFP area over time, although moderate CFP decreased and low CFP increased with active management (Fig. 3a-f). With climate change, there were increases in area in the low CFP class, and decreases in area in the high and moderate CFP classes across both management scenarios. Although trends were similar, the reasons were slightly different: both management scenarios projected more standreplacing wildfire (Fig. 1e, f) resulting in at least $50 \%$ of the forest type in a post-disturbance and early-seral condition (Fig. 2e, f), which was classified by FCCS as low CFP (Fig. 3a, b, A2). There was slightly greater low CFP area with active management (Fig. 3b) because a greater portion of the landscape was in an open, rather than dense, forest condition (Fig. 2f).

In moist mixed-conifer forests, without changing climate, high CFP increased with fire suppression only and decreased with active management (Fig. 3k,l). With changing climate, under both management scenarios the area in the low CFP class increased (Fig. 3g, h), the area in the moderate CFP class decreased slightly (Fig. 3i, j), and the area in the high CFP class substantially decreased (Fig. $3 \mathrm{k}, 1$ ). However, the mean increase in the area in the low CFP class and the mean decrease in the area in the high CFP class was greater under active management (Fig. 3h, 1). Divergent trends between the climate and no-climate-change simulations in high CFP reflect differences in area of dense forest with and without climate change (Fig. 2g, h), and the projected increase in wildfire with a changing climate (Fig. 1g, h).

\subsection{Standing timber volume}

Without climate change, standing timber volume remained relatively constant in dry mixedconifer forests, with similar values across management scenarios (Fig. 4a, b). With increasing wildfire under a changing climate, timber levels declined across management scenarios, although the decline was slightly greater, and the variance larger, under the fire suppression scenario. In moist mixed-conifer forests, without climate change, timber levels were higher
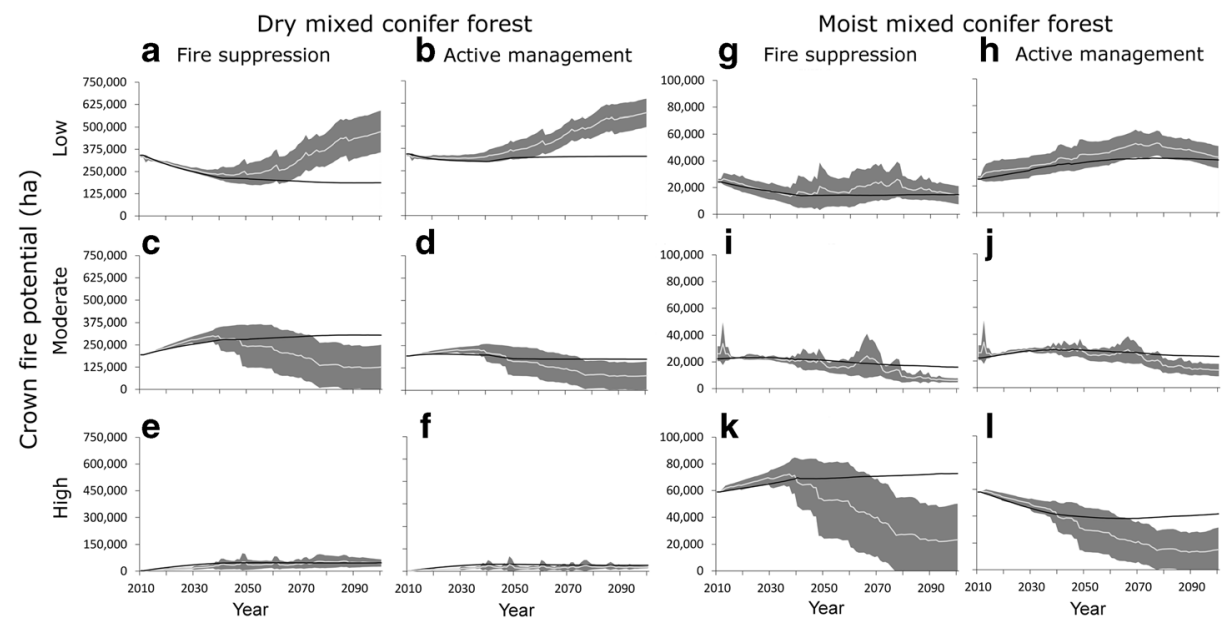

Fig. 3 Trends in crown fire potential (CFP) categories across climate-management scenarios. Black lines represent average CFP trends without climate change. White lines and shadings reflect climate ensemble means and one standard deviation 
with fire suppression (Fig. 4c, d). However, with climate change, slightly higher timber levels, and lower variation, were projected under active management.

\subsection{Potential wildlife habitat}

Without climate change, under the fire suppression scenario woodpecker and bluebird potential habitat declined as forests became denser, but marten potential habitat increased slightly (Fig. 5a). However, with more open ponderosa pine conditions under the active management scenario (Fig. 2b), bluebird potential habitat increased and marten potential habitat decreased (Fig. 5b). After an early decline, area in woodpecker potential habitat returned to near-initial levels with active management.

Under changing climate, woodpecker potential habitat declined irrespective of the management scenario, but rate of decline and loss in potential woodpecker habitat was greater under the fire suppression scenario (Fig. 5c, d). Woodpecker habitat declines reflected loss in moist mixedconifer forest area and an increase in post-disturbance conditions. Marten habitat was also projected to decrease, but general trends were similar irrespective of management. Conversely, bluebird potential habitat increased under climate change in both management scenarios, consistent with an increase in post-disturbance, a greater abundance of ponderosa pine in dry mixed-conifer forests, and more open structural conditions projected by the cSTSMs (Fig. 2).

\section{Discussion}

Broadly, our results suggest landscapes with more frequent disturbance intervals will likely become even more dynamic as disturbance frequencies continue to increase with climate change. Our projections also suggest changes in vegetation and fire associated with climate change are generally larger than those associated with management prescriptions, but that both

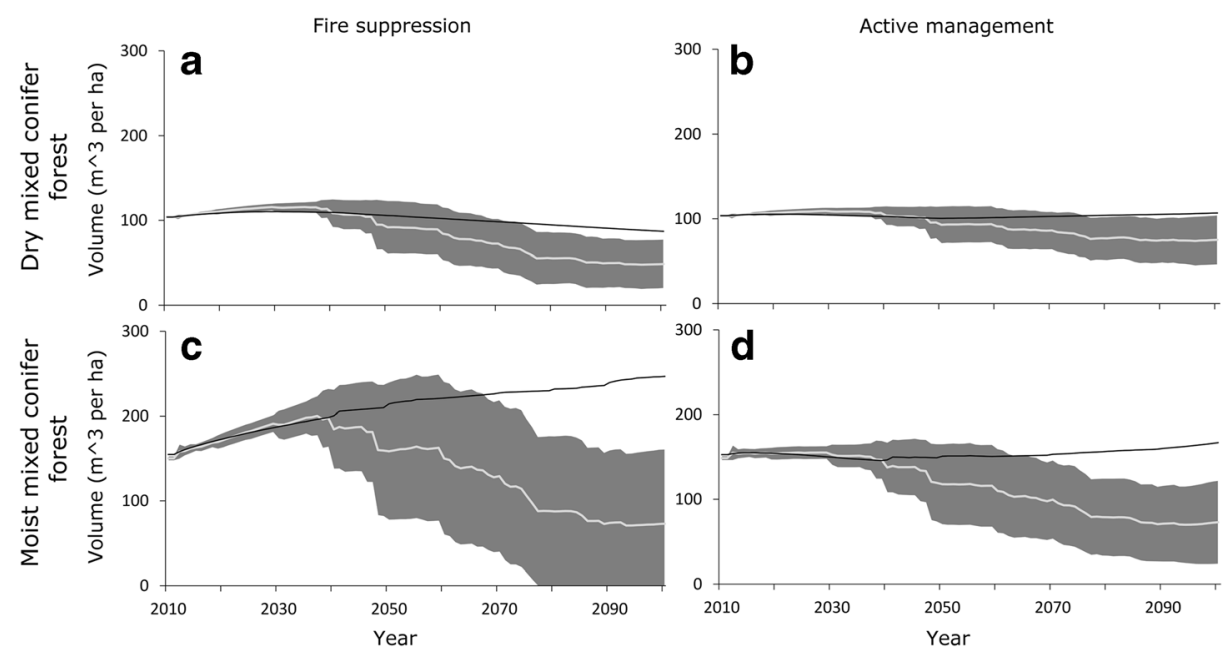

Fig. 4 Trends in standing timber volume. Standing timber includes all merchantable trees greater than $13 \mathrm{~cm}$ in quadratic mean diameter. Black line represents average trends without climate change. White lines and shadings reflect climate ensemble means and one standard deviation 


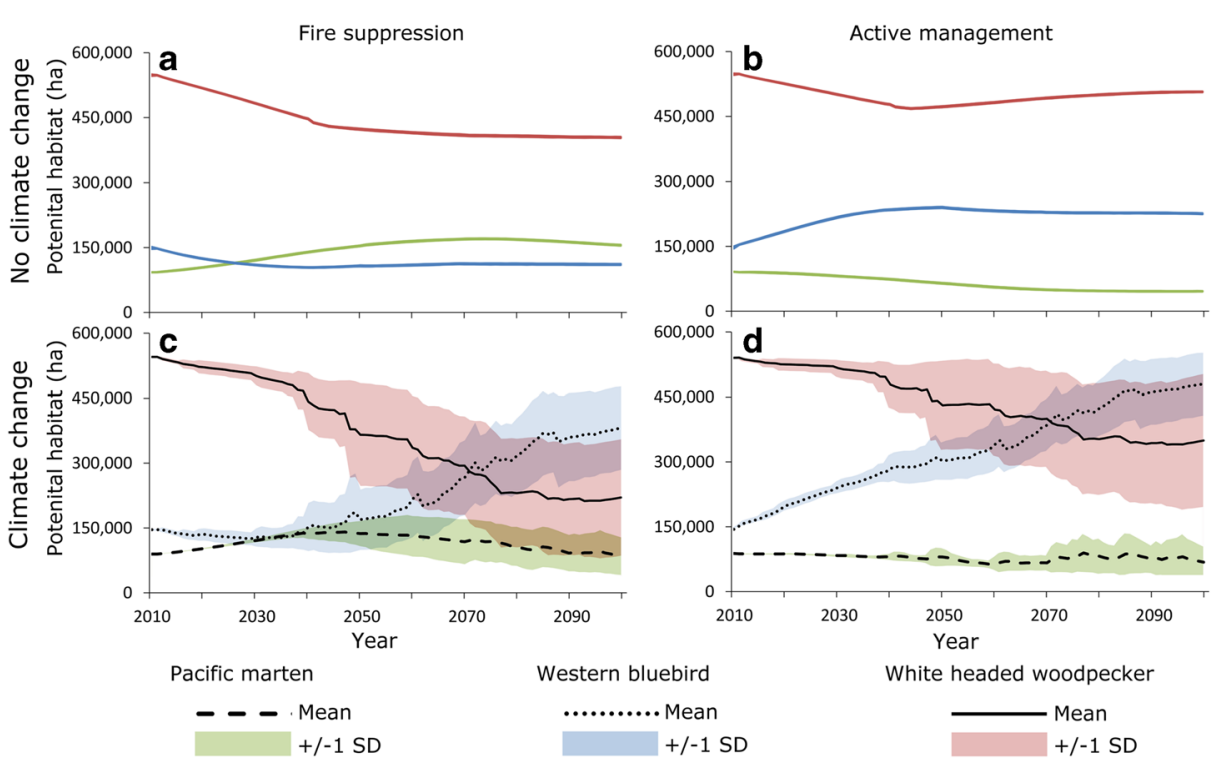

Fig. 5 Trends and variation in potential wildlife habitat for the American marten, western bluebird, and whiteheaded woodpecker

the rate and magnitude of change in any particular ecosystem service can be either positively or negatively influenced by active management.

\subsection{Climate change as a dominant driver of change in ecosystem services}

Our results suggest that the direction, rate, and magnitude of change in provisioning of ecosystem services will vary greatly depending on whether a static or warming climate is assumed, highlighting the importance of considering a changing climate in planning ecosystem management in the coming decades. For example, without climate change, model simulations showed increasing levels of timber volume over time, but under different climate change scenarios, timber volume declined to varying degrees (Fig. 4). Trends in wildlife habitat also vary substantially depending on the climate future. As expected, changes in ecosystem services under warming climate were driven in large part by significant increases in fire area burned (Seidl et al. 2016; Littell et al. 2010). The coarsest changes in overall trends in fire and ecosystem services were associated with climate change (versus the no-climate-change scenario), whereas active management typically affected a fine-tuning of those coarse changes (Figs. 2, 3, 4, and 5). These results illustrate climate-related increases in disturbances will likely be over-arching processes shaping broad-scale ecosystem change and our ability to sustain current values through time.

\subsection{Active management may moderate impacts of climate change-driven disturbances}

Our model projections suggest changes in vegetation and fire associated with climate will dictate broad-scale trends in ecosystem services, but that active forest management may dampen or slow some effects of climate-related disturbances on ecosystem services (Millar and Stephenson 2015; Stephens et al. 2014; Adams 2013). In our model simulations, the area 
burned under changing climate was substantial, exceeding the total forest area (i.e., a fire rotation well less than our 90-year study period), and increases in stand-replacing wildfire altered the area in each forest type. However, active management decreased the rate of transition from moist to dry mixed-conifer forests (Fig. 1). Furthermore, as found in Rocca et al. (2014) in montane forests of the Rocky Mountains, active management decreased the likelihood of highseverity fire under changing climate. Reductions in high-severity fire will likely be beneficial to species that depend on relatively dense moist mixed-conifer forests, such as Pacific marten and Northern spotted owl (Halofsky et al. 2014a, b). Although there were declines in timber under changing climate, our results indicate that active management may lessen these declines by reducing the incidence of high-severity fire also noted by Earles et al. (2014).

\subsection{Trends in wildlife habitat with climate change and management will be species-specific}

Trends in wildlife habitat may not be consistent with other management or societal objectives, and the ability to achieve various wildlife habitat goals under a changing climate will be species-specific. Disturbance-adapted or generalist species (e.g., Western bluebird) are likely to see an increase in potential habitat under changing climate with increases in area burned (Case et al. 2015), regardless of management. Specialist species are likely to be most negatively affected by changing climate (Montoya and Raffaelli 2010). In central Oregon, potential habitat for forest specialists associated with denser forests (e.g., Pacific marten) is unlikely to increase with a change in climate, because either high-severity wildfire or active management will likely result in a decrease in dense forest structure. Dense forest specialists may thus represent a management challenge under a changing climate, and in combination with other ecosystem services, illustrate how climate change will challenge societal expectations for maintaining current economic, ecological, and other societal values.

\subsection{Response to climate changes will vary spatially}

Although our models were run aspatially, climate change effects are likely to be highly variable depending on landscape position and context. For example, Qiu and Turner (2013) observed spatial variation in interactions among ecosystem services in a Wisconsin (USA) watershed. Similar findings were observed by Maes et al. (2012) in a spatial analysis for Europe. Because our cSTSM runs were not fully spatially explicit, we did not capture this spatial variation, and it is possible some results would have been different with spatial model runs. For example, cumulative area burned exceeded forest area, but our results cannot determine if the entire landscape burned or if certain locations burned multiple times. Similarly, for wildlife habitat, we did not consider factors such as patch area, shape, and configuration. In considering future trends and possible management actions under changing climate, it will be critical to consider spatial variation in climate changes and species response (Morelli et al. 2016).

\section{Conclusions}

Quantitative analyses projecting ecosystem services into the future under a changing climate are rare. Broadly, our results suggest landscapes with more frequent disturbance intervals will likely become even more dynamic as disturbance frequencies, and associated variability in 
ecosystem services, continue to increase. Our projections suggest many ecosystem service goals are unlikely to be sustainable in dry forests at current levels in a changing climate. Adaptation in the form of active management may ameliorate some negative effects of increased disturbance, but loss in the provisioning of some ecosystem services is likely, and society may need to prepare for these losses.

Acknowledgements We thank J. Barbour, A. Brodie, and A. Estep for project support, D. Bachelet and D. Conklin for running $\mathrm{MC1}$, J. Campbell for manuscript improvements, and thoughtful comments from two anonymous reviewers. This work was conducted as part of the Integrated Landscape Assessment Project, which was funded by the American Recovery and Reinvestment Act, the USDA Forest Service Pacific Northwest Research Station, the USDA Forest Service Pacific Northwest Region, and the USDA Forest Service Southwest Region. Any opinions, findings, and conclusions or recommendations expressed in this material are those of the author(s) and do not necessarily reflect the views of the funding or parent organization(s).

\section{References}

Adams MA (2013) Mega-fires, tipping points and ecosystem services: managing forests and woodlands in an uncertain future. For Ecol Manag 294:250-261

Apex and ESSA (2011) Path landscape model online documentation. Apex Resource Management Solutions Ltd. and ESSA Technologies Ltd, Ottawa, http://www.apexrms.com

Bachelet D, Lenihan J, Daly C et al (2001) MC1: a dynamic vegetation model for estimating the distribution of vegetation and associated carbon, nutrients, and water - technical documentation. Version 1.0. Gen. Tech. Rep. PNW-GTR-508. Portland, OR: U.S. 95 p.

Bachelet D, Ferschweiler K, Sheehan TJ et al (2015) Projected carbon stocks in the conterminous USA with land use and variable fire regimes. Glob Change Biol 21:4548-4560

Case MJ, Lawler JJ, Tomasevic JA (2015) Relative sensitivity to climate change of species in northwestern North America. Biol Conserv 187:127-133

Daly C, Halbleib M, Smith JI et al (2008) Physiographically sensitive mapping of climatological temperature and precipitation across the conterminous United States. Int J Climatol 28:2031-2064

Daniel CJ, Frid L (2012) Predicting landscape vegetation dynamics using state-and-transition simulation models. In: Kerns BK, Shlisky AJ, Daniel CJ (eds) Proceedings of the First Landscape State-and-Transition Simulation Modeling Conference, Portland, OR, USA, 14-16 June 2011, pp 5-22.

Earles JM, North MP, Hurteau MD (2014) Wildfire and drought dynamics destabilize carbon stores of firesuppressed forests. Ecol Appl 24:732-740

Elkin C, Gutiérrez AG, Leuzinger S et al (2013) A $2{ }^{\circ} \mathrm{C}$ warmer world is not safe for ecosystem services in the European Alps. Glob Chang Biol 19:1827-1840

Federal Register. 2012. 36 CFR Part 219. RIN 0596-AD02. National Forest System land management planning, final rule and record of decision. 77:21162-21276. Washington, DC: U.S. Department of Agriculture, Forest Service

Fischlin A, Midgley GF, Price JT et al (2007) Ecosystems, their properties, goods, and services. In: Parry ML, Canziani OF, Palutikof JP et al (eds) Climate change 2007: impacts, adaptation and vulnerability. Contribution of Working Group II to the Fourth Assessment Report of the Intergovernmental Panel on Climate. Cambridge University Press, Cambridge, pp 211-272

Fowler HJ, Blenkinsop S, Tebaldi C (2007) Linking climate change modeling to impacts studies: recent advances in downscaling techniques for hydrological modeling. Int J Climatol 27:1547-1578

Gordon HB, Rotstayn JL, McGregor MR et al (2002) The CSIRO Mk3 climate system model. CSIRO Atmospheric Research technical paper no. 60. CSIRO Atmospheric Research

Groffman PM, Kareiva P, Carter S et al (2014) Ch. 8: ecosystems, biodiversity, and ecosystem services. In: Melillo JM, Richmond TC, Yohe GW (eds) Climate change impacts in the United States: the Third National Climate Assessment. U.S. Global Change Research Program, pp 195-219

Halofsky JE, Hemstrom MA, Conklin DR et al (2013) Assessing potential climate change effects on vegetation using a linked model approach. Ecol Model 266:131-143

Halofsky JS, Halofsky JE, Burcsu T et al (2014a) Potential effects of climate change and management in dry forests of central Oregon. Ecol Appl 24:1908-1925 
Halofsky JE, Creutzburg, MK, Hemstrom, MA (eds) (2014a) Integrating social, economic, and ecological values across large landscapes. Gen. Tech. Rep. PNW-GTR-896. Portland, OR: U.S. Department of Agriculture, Forest Service, Pacific Northwest Research Station. $206 \mathrm{p}$

Hasumi H, Emori S (eds) (2004) K-1 coupled model (MIROC) description. Technical Report 1. University of Tokyo, Center for Climate System Research, Tokyo, Japan

Henderson JA, Lesher RD, Peter DH, Ringo CD (2011) A landscape model for predicting potential natural vegetation of the Olympic Peninsula USA using boundary equations and newly developed environmental variables. Gen. Tech. Rep. PNW-GTR-841. Portland, OR: U.S. Department of Agriculture, Forest Service, Pacific Northwest Research Station. 35 p

Hessburg PF, Spies TA, Perry DA et al (2016) Tamm review: management of mixed-severity fire regime forests in Oregon, Washington, and Northern California. For Ecol Manag. In press

IPCC [Intergovernmental Panel on Climate Change] (2007) Contribution of Working Group I to the Fourth Assessment Report of the Intergovernmental Panel on Climate Change. In: Solomon S, Qin D, Manning M, Chen $\mathrm{Z}$ et al (eds) Cambridge University Press. Cambridge, United Kingdom and New York, New York, USA

Johns TC, Gregory JM, Ingram WJ et al (2003) Anthropogenic climate change for 1860 to 2100 simulated with the HadCM3 model under updated emissions scenarios. Clim Dyn 20:583-612

Littell JS, Oneil EE, McKenzie D et al (2010) Forest ecosystems, disturbance, and climatic change in Washington State, USA. Climatic Change 102:129-158

Maes J, Paracchini ML, Zulian G et al (2012) Synergies and trade-offs between ecosystem service supply, biodiversity, and habitat conservation status in Europe. Biol Conserv 155:1-12

Merschel AG, Spies TS, Heyerdahl EK (2014) Mixed-conifer forests of central Oregon: effects of logging and fire exclusion vary with environment. Ecol Appl 24:1670-1688

Millar CI, Stephenson NL (2015) Temperate forest health in an era of emerging megadisturbance. Science 349: 823-826

Millennium Ecosystem Assessment (2005) Living beyond our means: natural assets and human well-being. Island Press, Washington, D.C

Mina M, Bugmann H, Cordonnier T et al (2016) Future ecosystem services from European mountain forests under climate change. J Appl Ecol. doi:10.1111/1365-2664.12772

Montoya JM, Raffaelli D (2010) Climate change, biotic interactions and ecosystem services. Philos T Roy Soc B 365:2013-2018

Morelli TL, Daly C, Dobrowski SZ et al (2016) Managing climate change refugia for climate adaptation. PLoS One 11: p.e0159909

Nakićenović N, Swart R (eds) (2000) Special report on emissions scenarios. A special report of Working Group III of the Intergovernmental Panel on Climate Change. Cambridge University Press, Cambridge

Ohmann J, Gregory MJ (2002) Predictive mapping of forest composition and structure with direct gradient analysis and nearest neighbor imputation in coastal Oregon, U.S.A. Can J Forest Res 32:725-741

PRISM Group (2012) Parameter-elevation Regressions on Independent Slopes Model climate mapping system [online]. http://www.prism.oregonstate.edu/

Qiu J, Turner MG (2013) Spatial interactions among ecosystem services in an urbanizing agricultural watershed. Proc Natl Acad Sci U S A 110:12149-12154

Rocca ME, Brown PM, MacDonald LH et al (2014) Climate change impacts on fire regimes and key ecosystem services in Rocky Mountain forests. Forest Ecol Manag 327:290-305

Rogers BM, Neilson RP, Drapek et al (2011) Impacts of climate change on fire regimes and carbon stocks of the U.S. Pacific Northwest. J Geophys Res 116:G03037

Seidl R, Spies TA, Peterson DL et al (2016) Searching for resilience: addressing the impacts of changing disturbance regimes on forest ecosystem services. J Appl Ecol 53:120-129

Stephens SL, Burrows N, Buyantuyev A et al (2014) Temperate and boreal forest mega-fires: characteristics and challenges. Front Ecol Environ 12:115-122

Stavros EN, Abatzoglou JT, McKenzie D et al (2014) Regional projections of the likelihood of very large wildland fires under a changing climate in the contiguous Western United States. Climatic Change 126:455468

Stine, P, Hessburg, P, Spies, T, et al (2014) The ecology and management of moist mixed-conifer forests in eastern Oregon and Washington: a synthesis of the relevant biophysical science and implications for future land management. Gen. Tech. Rep. PNW-GTR-897. Portland, OR: U.S. 254 p.

Tempereli C, Bugmann H, Elkin C (2012) Adaptive management for competing forest goods and services under climate change. Ecol Appl 22:2065-2077 